\title{
Membranous type matrix metalloproteinase 16 induces human prostate cancer metastasis
}

\author{
CHUNWA JIANG ${ }^{1}$, JUANJING WANG $^{1}$, CHEN DONG $^{1}$, WEI WEI $^{2}$, JIANG LI $^{2}$ and XIAOMENG LI ${ }^{1}$ \\ ${ }^{1}$ The Key Laboratory of Molecular Epigenetics of Ministry of Education, Institute of Genetics and Cytology, \\ Northeast Normal University, Changchun, Jilin 130024; ${ }^{2}$ Department of Prosthodontics, \\ Dental Hospital, Jilin University, Changchun, Jilin 130021, P.R. China
}

Received February 5, 2016; Accepted March 3, 2017

DOI: $10.3892 / \mathrm{ol} .2017 .6536$

\begin{abstract}
Matrix metalloproteinases (MMPs) are a family of proteolytic enzymes, which perform a crucial role in the metastatic spread of cancer. MMP2 and MMP9 are important cancer-associated MMPs in the invasion and metastasis of the majority of carcinomas. As a new member of the membrane-type MMPs, the function of MMP16 associated with invasion and metastasis of cancer remains unclear. In the present study, MMP16 expression in prostate cancer (PCa) tissues and cells was examined, and the high expression of MMP16 was revealed to be associated with advanced prostate tumor stage and PCa cell metastasis. The membrane localization of MMP16 is required for its function. To the best of our knowledge, the present study is the first to demonstrate that MMP16 is associated with advanced prostate tumor stage. As an important mediator of PCa cell metastasis, the membrane localization of MMP16 is required, and MMP16 may be an ideal target candidate for preventing PCa cell metastasis.
\end{abstract}

\section{Introduction}

Prostate cancer (PCa) ranks as the most prevalent type of cancer affecting male adults in the world (1). Despite local therapy, $40 \%$ of patients with PCa eventually develop metastases (2). Subsequent to the occurrence of metastasis, $\mathrm{PCa}$ progresses to an aggressive disease and poses an increased risk of mortality (3). Thus, improved understanding of the

Correspondence to: Professor Xiaomeng Li, The Key Laboratory of Molecular Epigenetics of Ministry of Education, Institute of Genetics and Cytology, Northeast Normal University, 5268 People's Street, Changchun, Jilin 130024, P.R. China

E-mail: lixm441@nenu.edu.cn

Professor Jiang Li, Department of Prosthodontics, Dental Hospital, Jilin University, 1500 Tsinghua Road, Changchun, Jilin 130021, P.R. China

E-mail: ljiang@jlu.edu.cn

Key words: matrix metalloproteinase 16, prostate cancer, prostate tumor stage, metastasis, invasion, transmembrane location molecular mechanisms involved in $\mathrm{PCa}$ metastasis may be helpful for the effective control of PCa.

One of the earliest events in the metastatic spread of cancer is the proteolytic degradation of the extracellular matrix proteins and invasion through the basement membrane. Matrix metalloproteinases (MMPs) are a family of proteolytic enzymes that degrade the extracellular matrix, as well as a variety of cell surface receptors or signaling molecules $(4,5)$. MMPs perform a crucial role in the metastatic spread of cancer $(6,7)$. MMP2 and MMP9 are the most important cancer-associated zinc-dependent endopeptidases in the invasion and metastasis of the majority of carcinomas, including in brain neoplasms, human breast cancer and colon cancer (8-10). High expression levels of activated MMP2 or MMP9 have been associated with metastasis in patients with PCa $(11,12)$.

MMP16 (also termed MT3-MMP) belongs to the membrane-type MMPs, a subgroup of the MMP family. MMP16 was originally cloned from a human placenta cDNA library, and was demonstrated to be located in the cell membrane (13). MMP16 exhibits a high expression level in a variety of tumors tissues, including gastric cancer, astrocytoma and melanoma, compared with normal tissues (14-16), indicating its potential biological function. A previous study reported that the migration and invasion of gliomas was mediated by MMP16 (17), which indicated that the expression of the MMP16 gene may be associated with tumor cell invasion and metastasis. However, it is not clear whether MMP16 is actually involved in the invasion and metastasis of PCa.

In the present study, the association of MMP16 expression with advanced prostate tumor stage and PCa metastasis was first investigated. It was also examined whether the membrane localization of MMP16 is required for its function. MMP16 may be qualified to be a therapeutic target of PCa metastasis.

\section{Materials and methods}

Plasmids and cell culture. pcDNA3.1-MMP16 was kindly by $\mathrm{Dr}$ Stephen J. Weiss from the University of Michigan (Ann Arbor, MI, USA) (18). psecTAGhygro-MMP16 [ $\Delta 533$ aspartic acid (Asp)] was provided by Dr Alyson E. Fournier from Montreal Neurological Institute in McGill University (Montreal, QC, Canada) (19). 
LNCaP, PC3 and DU145 were purchased from American Type Culture Collection, (Manassas, VA, USA). LNCaP was cultured in T-medium (custom formula no. 02-0056DJ; Gibco; Thermo Fisher Scientific, Inc., Waltham, MA, USA), PC3 and DU145 cells were cultured in Dulbecco's modified Eagle's medium (DMEM), supplemented with $10 \%$ fetal bovine serum (FBS; Sijiqing Biological Engineering Materials Co., Ltd., Hangzhou, China), $4 \mathrm{mM}$ glutamine, $100 \mathrm{U} / \mathrm{ml}$ penicillin and $100 \mu \mathrm{g} / \mathrm{ml}$ streptomycin in a humidified $5 \% \mathrm{CO}_{2}$ atmosphere at $37^{\circ} \mathrm{C}$.

Synthetic small interfering RNAs (siRNAs). All siRNAs were purchased from Genepharma, Inc. (Genepharma, Inc., Sunnyvale, CA, USA). The sequences for MMP16 siRNAs were: Forward, 5'-CGUGAUGUGGAUAUAACCAtt-3' and reverse, 5'-UGGUUAUAUCCACAUCACGtt-3', and the negative control sequence was forward, 5'-UUCUCCGAACGUGUCACGUtt-3', reverse, 5'-ACGUGACACGUUCGGAGAAtt-3'.

Transient transfection. LNCaP and PC3 cells were seeded onto 6-well plates, and reached 50-60\% confluency on the day of transfection. Each well was transfected with $1 \mu \mathrm{g}$ of DNA, including MMP16 and MMP16 (D533Asp), using polyethylenimine (Eurogentec, Liege, Belgium), according to the manufacturer's protocol in LNCaP cells. To knockdown MMP16, PC3 cells were transfected with $50 \mathrm{nM}$ Dicer and the negative control siRNA using RNAi-mate transfection reagent (Genepharma, Inc.) at the final concentration of $50 \mathrm{nM}$, and incubated for an additional $48 \mathrm{~h}$.

Immunohistochemical staining. A total of 6 paraffin-embedded PCa tissue specimens were acquired from the Jilin University Hospital (Jilin, China) and sliced into $4-\mu \mathrm{m}$ sections. Patients with PCa were divided into 2 groups: Non-metastasis cases [tumor $(\mathrm{T})_{1-4}$ lymph-node $(\mathrm{N})_{0}$ metastasis $(\mathrm{M})_{0}$ ] and metastasis cases $\left(\mathrm{T}_{1-4} \mathrm{~N}_{1-2} \mathrm{M}_{0}\right.$ or $\left.\mathrm{T}_{1-4} \mathrm{~N}_{0-2} \mathrm{M}_{1}\right)$. The present study received ethical approval from the Commission for Scientific Research in Jilin University, and was administered in accordance with the ethical standards of the Declaration of Helsinki, second revision. Informed consent was obtained from all individual patients involved in the present study. The specimens were reactivated by heating for $3 \mathrm{mins}$ at $100^{\circ} \mathrm{C}$, and $3 \%$ hydrogen peroxide in methanol was then added to destroy the endogenous peroxidase activity. In total, $3 \mu \mathrm{g} / \mathrm{ml}$ of anti-MMP16 polyclonal antibody (1:1,000 dilution; cat. no. BS1234; Bioworld Technology, Inc., St. Louis Park, MN, USA) was applied overnight at $4^{\circ} \mathrm{C}$, and the secondary antibody (horseradish peroxidase-conjugated anti-rabbit immunoglobulin $\mathrm{G}$ antibody; 1:1,000 dilution; cat. no. sc-53804; Santa Cruz Biotechnology, Inc., Dallas, TX, USA) was then applied for $1 \mathrm{~h}$ at $25^{\circ} \mathrm{C}$. For immunohistochemical staining, an EliVision plus kit (Maixin Bio, Fuzhou, China) was used according to the manufacturer's protocol. Diaminobenzidine (cat. no. GK600505; Shanghai Gene Technology Co., Ltd., Shanghai, China) staining was performed followed by counterstaining with hematoxylin (cat. no. AR-0711; Beijing Dingguo Changsheng Biotechnology Co., Ltd., Beijing, China). ImagePro Plus software (version IPP6.0; Media Cybernetics, Inc., Rockville, MD, USA) was used to analyze the integrated optical density (IOD) values of the positive areas of MMP16 immunohistochemical staining. All brown-stained vessels were counted under 3 fields with x200 power. The mean value of the vessels in the 3 fields was taken.

Immunoblotting. LNCaP, PC3 and DU145 cells, or the transfected cells as previously described in the 6-well plate, were rinsed twice with ice-cold PBS and lysed in radioimmunoprecipitation assay buffer supplemented with the protease inhibitors dithiothreitol (cat. no. CD116-1G) and phenylmethylsulfonyl fluoride (cat. no. LP250-10G) (both from Beijing Dingguo Changsheng Biotechnology Co., Ltd.). Equal amounts of protein were analyzed by western blotting using antibodies against MMP16 (1:1,000 dilution; cat. no. BS1234; Bioworld Technology, Inc.) and $\beta$-actin (mouse anti-human; 1:1,000 dilution; cat. no. sc-47778; Santa Cruz Biotechnology, Inc.).

Low-melt agarose drop migration assay. The solution of melted $0.3 \%$ low melting-point agarose with DMEM, without or with $10 \%$ FBS, was prepared. LNCaP, PC3 and DU145 cells, or the transfected cells, were digested by $0.25 \%$ trypsinization, resuspended in the solution without FBS at a concentration of $4 \times 10^{7}$ cells $/ \mathrm{ml}$, and warmed in at $37^{\circ} \mathrm{C}$. Drops of the cell suspension $(2 \mu \mathrm{l})$ were plated at the center of the wells in a 24-well tissue culture plate. The plate was stored at $4^{\circ} \mathrm{C}$ for 25 mins to allow the agarose drop to set. Once the drops were set, the solution of DMEM with $10 \%$ FBS was added to melted $0.3 \%$ low melting-point agarose, and the plate was stored at $4^{\circ} \mathrm{C}$ for 30 mins to allow the agarose drop to set. Subsequently, the plate was moved to a $37^{\circ} \mathrm{C}$ incubator. Images of cell migration were captured at 48 and $96 \mathrm{~h}$.

In vitro wound healing assay. The transfected $\mathrm{LNCaP}$ and PC3 cells were cultured as confluent monolayers on 6-well plates and synchronized in $1 \%$ FBS for $24 \mathrm{~h}$. The monolayer was wounded by removing a 300-500 $\mu \mathrm{m}$ strips of cells across the well with a $200 \mu \mathrm{l}$ pipette tip, and then washed twice with cold PBS to remove non-adherent cells. Wound healing was quantified at 0, 48 and $96 \mathrm{~h}$. ImagePro Plus software (Media Cybernetics, Inc.) was used to analyze the area of the wound edge.

Transwell invasion assays. The transfected LNCaP and PC3 cells were seeded on the top of a culture plate (Costar; Corning Incorporated, Corning, NY, USA) containing a polycarbonate filter (diameter, $6.5 \mathrm{~mm}$; pores, $8 \mu \mathrm{m}$ ) pre-coated with fibronectin $(0.5 \mathrm{mg} / \mathrm{ml})$. The upper chamber contained cells in T-medium/DMEM plus $1 \% \mathrm{FBS}$, and the lower chamber contained T-medium/DMEM plus $10 \%$ (chemoattractant) or $1 \%$ FBS (control). Cells were incubated for $12 \mathrm{~h}$ at $37^{\circ} \mathrm{C}$ in an atmosphere containing $5 \% \mathrm{CO}_{2}$. The cells that did not migrate were wiped away from the top of the Transwell filter and the migrated cells on the bottom surface were counted following staining with coomassie blue (Beijing Dingguo Changsheng Biotechnology Co., Ltd.). The cells were counted under a light microscope (magnification, x200).

Statistical analysis. SPSS 17.0 software (SPSS, Inc., Chicago, IL, USA) was used to evaluate the statistical variability. All the experiments were performed $\geq 3$ times. The data were expressed as the mean \pm standard deviation. Two-tailed 
A

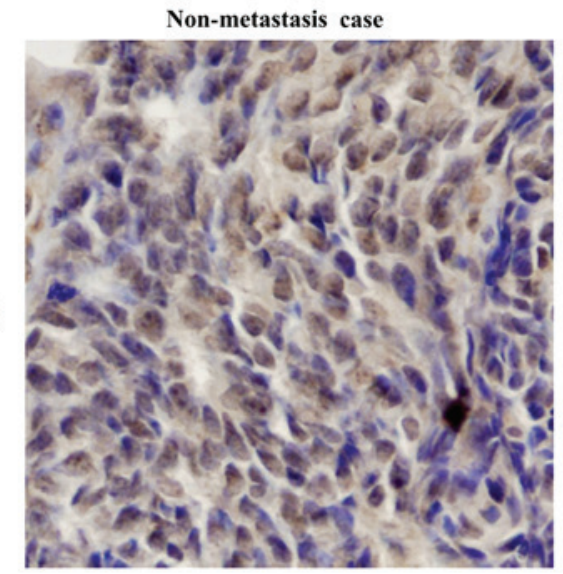

MMP16

MMP16

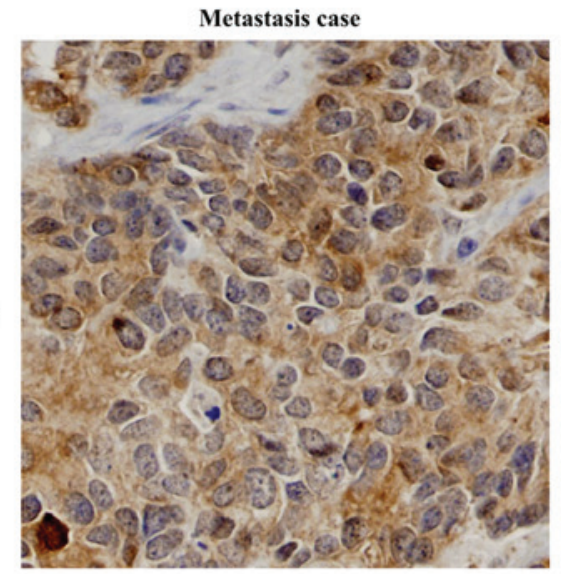

$\mathbf{C}$

Non-metastasis

Metastasis

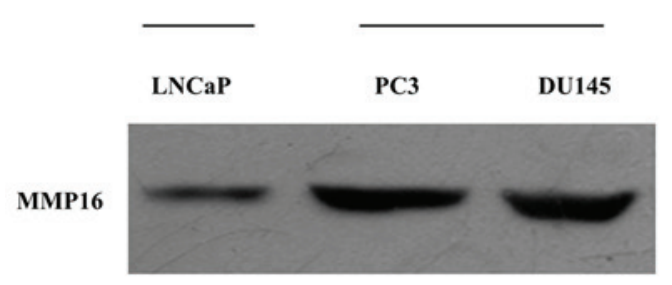

$\beta$-actin

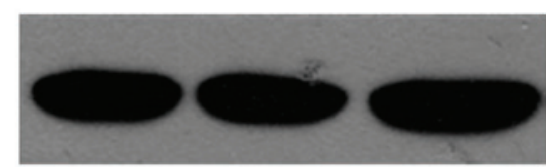

B

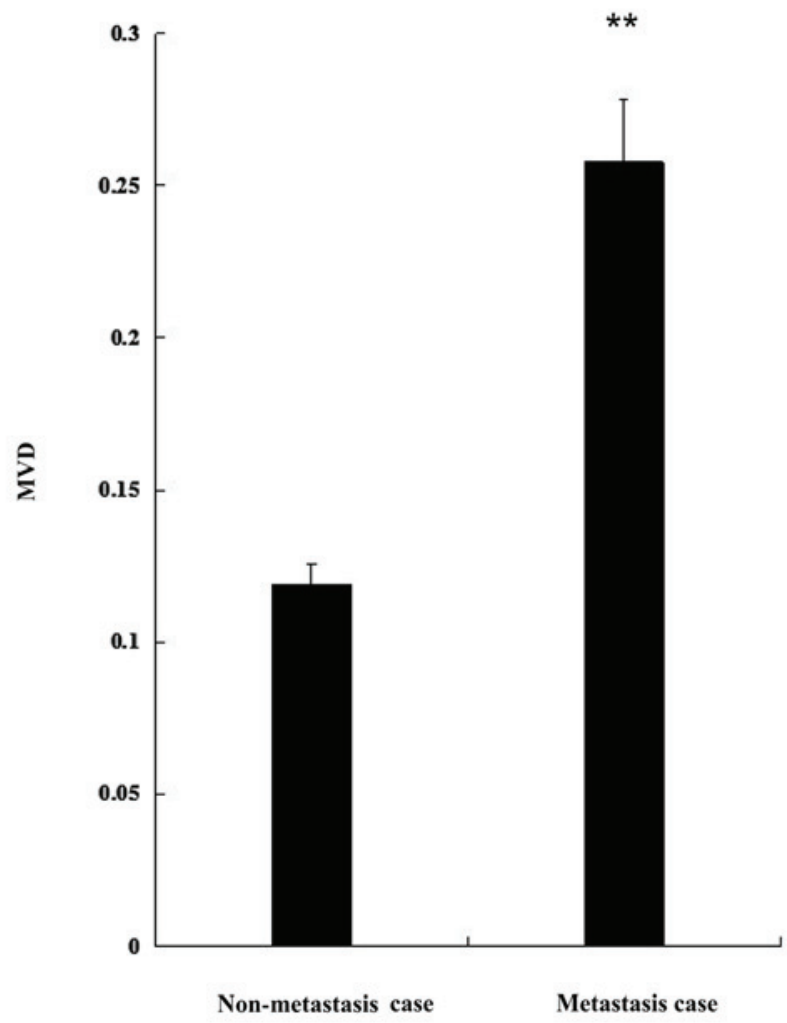

D

LNCaP

PC3

DU145
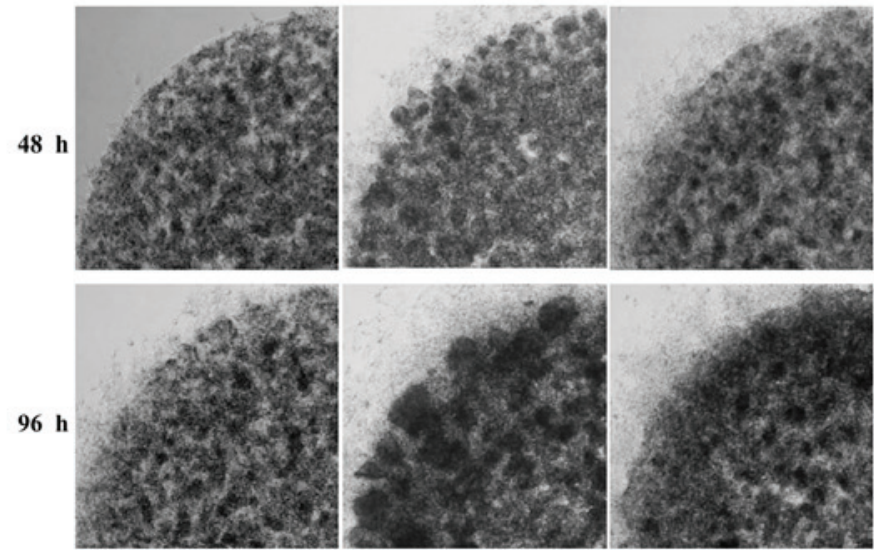

Figure 1. Expression of MMP16 in metastatic PCa tissues was increased compared with non-metastatic PCa tissues and cells. (A) MMP16 expression was evaluated by immunohistochemistry in non-metastatic PCa tissues and metastatic PCa tissues. (B) MMP16 expression was analyzed by ImagePro Plus software and the mean values of the tumor were taken as the microvascular density count. The expression of MMP16 was significantly increased in metastatic PCa tissues compared with non-metastatic tissues ( $\left.{ }^{* *} \mathrm{P}<0.01\right)$. (C) Endogenous MMP16 expression was detected by western blot analysis in 3 different PCa cell lines. $\beta$-actin was used for normalization. (D) The metastatic capacities of LNCaP, PC3 and DU145 cells were compared by low-melt agarose migration assays. MMP16, matrix metalloproteinase 16; PCa, prostate cancer.

student's t-tests were used to compare means of two independent groups. One-way analysis of variance was applied to analyze the difference of means in $\geq 2$ groups. $\mathrm{P}<0.05$ was considered to indicate a statistically significant difference.

\section{Results}

Increased MMP16 expression is associated with PCa malignancy. Although the expression of MMP16 is high in a variety of tumor tissues, the association between the expression level and PCa malignancy remains to be elucidated.

To determine whether MMP16 is relevant to $\mathrm{PCa}$ malignancy, MMP16 expression was evaluated by immunohistochemistry in PCa tissue samples. The samples were classified into 2 groups according to clinical stage (non-metastasis and metastasis). MMP16 expression level was quantified as the IOD values of the positive areas of MMP16. Representative immunostaining is shown in Fig. 1A. MMP16 expression was 
significantly increased in the metastatic tissues when compared with the non-metastatic tissues in Fig. 1B, indicating that high levels of MMP16 may be associated with advanced prostate tumor stage.

MMP16 expression was also examined in 3 typical PCa cell lines: LNCaP, PC3 and DU145. These cell lines demonstrated differential metastasis capacity; LNCaP cells had the lowest metastasis capacity compared with the other two cell lines. The level of MMP16 expression was examined by western blot analysis in the $3 \mathrm{PCa}$ cell lines. As shown in Fig. $1 \mathrm{C}$, LNCaP cells had lower expression level of MMP16. By contrast, the other two cell lines (PC3 and DU145) had increased levels of MMP16 expression. The invasion ability of the three types of cells was also examined using the low-melt agarose migration assay. As shown in Fig. 1D, the LNCaP cell line had a weaker ability in cell migration, while PC3 and DU145 had high abilities in cell migration. This indicated that there may be a positive association between MMP16 protein expression level and PCa cell metastasis.

Endogenous MMP16 contributes to PC3 cells migration and invasion. To test the association of MMP16 protein expression level and PCa cell metastasis, the involvement of endogenous MMP16 in regulating the migration and invasion of PC3 cells was examined with the RNA interference method, using the low-melt agarose migration assay, the in vitro wound healing assay and the Transwell cell migration assay. MMP16 can be significantly knocked down by MMP16-siRNA (Fig. 2A). As shown in Fig. 2B, MMP16 knockdown led to inhibition of the migration of PC3 cells in the low-melt agarose migration assay. The migration of PC3 cells was then examined with the in vitro wound healing assay, and MMP16 siRNA was revealed to decrease the migration ratio of PC3 cells (Fig. 2C). In addition, the Boyden chamber assay was performed as an in vitro model of invasive migration of $\mathrm{PC} 3$ transfected with MMP16-siRNA or control siRNA. Cells migrated from the upper $1 \%$ of FBS to the lower $10 \%$ of FBS through the $8 \mu \mathrm{m}$ pores in the Boyden chamber. The migration rate of cells transfected with MMP16-siRNA was significantly lower compared with those transfected with MMP16-siRNA (Fig. 2D). In addition, MMP16-siRNA transfection did not affect PC3 cellular proliferation in the MTT assay (Fig. 2E).

Overexpressed membranous MMP16 promotes LNCaP cell migration and invasion. The effects of MMP16 on the migration and invasion of LNCaP cells in which MMP16 protein level was low was then examined. Wild-type MMP16 expression plasmid or MMP16- $\Delta 533$ Asp plasmid was transected with the deletion of 533 aspartic acid, which is necessary for the membrane localization of MMP16. Western blot analysis results revealed that the two plasmids expressed the same size protein (Fig. 3A). Low melting agarose cell migration assays, in vitro wound healing assays and Transwell cell migration assays were then performed to examine the differential impact of the two plasmids on cell invasion. Overexpression of the membrane type MMP16 significantly promoted cell migration. However, when MMP16- $\Delta 533 \mathrm{Asp}$ was localized in the cytoplasm, it lost the promotion function in cell migration as well as cell invasion (Fig. 3B-D), indicating that MMP16 expression in the cell membrane performs an important role in promoting cell migration and invasion. In addition, the effects of wild-type MMP16 and MMP16- 4533 Asp in cellular proliferation were also examined. No significant changes in cellular proliferation ability were observed for the two MMP16 plasmids when overexpressed in MTT assays (Fig. 3E). These results indicated that MMP16 is a new member of MMPS associated with cell metastasis ability in PCa, and their function to promote cell metastasis is dependent on its cell membrane localization.

\section{Discussion}

The expression of MMPs has been reported to be upregulated in various types of cancer, including in lung, pancreatic, breast and prostate cancer (20-26). While the majority of studies were mainly focused on the collagenase and gelatinase MMPs, studies on the membrane type MMPs are limited (27-29). MMP16 is a new member of membrane-type MMPs. Although the expression of MMP16 is high in a variety of tumor tissues, the association between the expression level and PCa malignancy remains to be elucidated.

The present results revealed that MMP16 expression was increased in metastatic PCa tissues compared with in non-metastatic PCa tissues, indicating that high level of MMP16 may be associated with advanced prostate tumor stage. MMP16 expression was also examined in the 3 typical PCa cell lines LNCaP, PC3 and DU145. LNCaP cell lines with lowest metastasis capacity had relatively lower expression level of MMP16. By contrast, the other two cell lines (PC3 and DU145) had increased levels of MMP16 expression. This is consistent with the previous study by Daja et al (30), in which MMP16 was shown to be increased in more invasive PCa sublines.

MMPs, including the two most important members MMP2 and MMP9, perform a crucial role in the invasion and metastasis of cancer. A number of previous studies have reported that MMP16 was associated with cell migration and cell invasion in certain cancers, including colorectal cancer, glioma cancer and melanoma (31-33). However, the role of MMP16 in regulating PCa cell invasion and metastasis has yet to be elucidated. In the present study, knockdown of MMP16 by siRNA was shown to inhibit PC3 cell migration and invasion. Consistently, overexpression of MMP16 also promoted LNCaP cell migration and invasion without affecting cellular proliferation. These results suggest that as a new member of MMPs, MMP16 is associated with cell metastasis in PCa. In addition, MMP16 with a deletion of 533 aspartic acid, which is necessary for the membrane localization of MMP16, lost the capability for promoting cell migration and invasion. These results suggested that as an important mediator of PCa cell metastasis, the transmembrane location of MMP16 is required for its function. This is consistent with a previous study, which demonstrated that the transmembrane domain of MT-MMPs in the carboxyl-terminus of their molecules exhibits the function of activating downstream pro-MMP2 (34).

To the best of our knowledge, the present study is the first to show that MMP16 is associated with advanced prostate tumor stage. As an important mediator of PCa cell metastasis, the membrane localization of MMP16 is required for its function. These results suggest that MMP16 may be qualified to be a therapeutic target for PCa metastasis. 

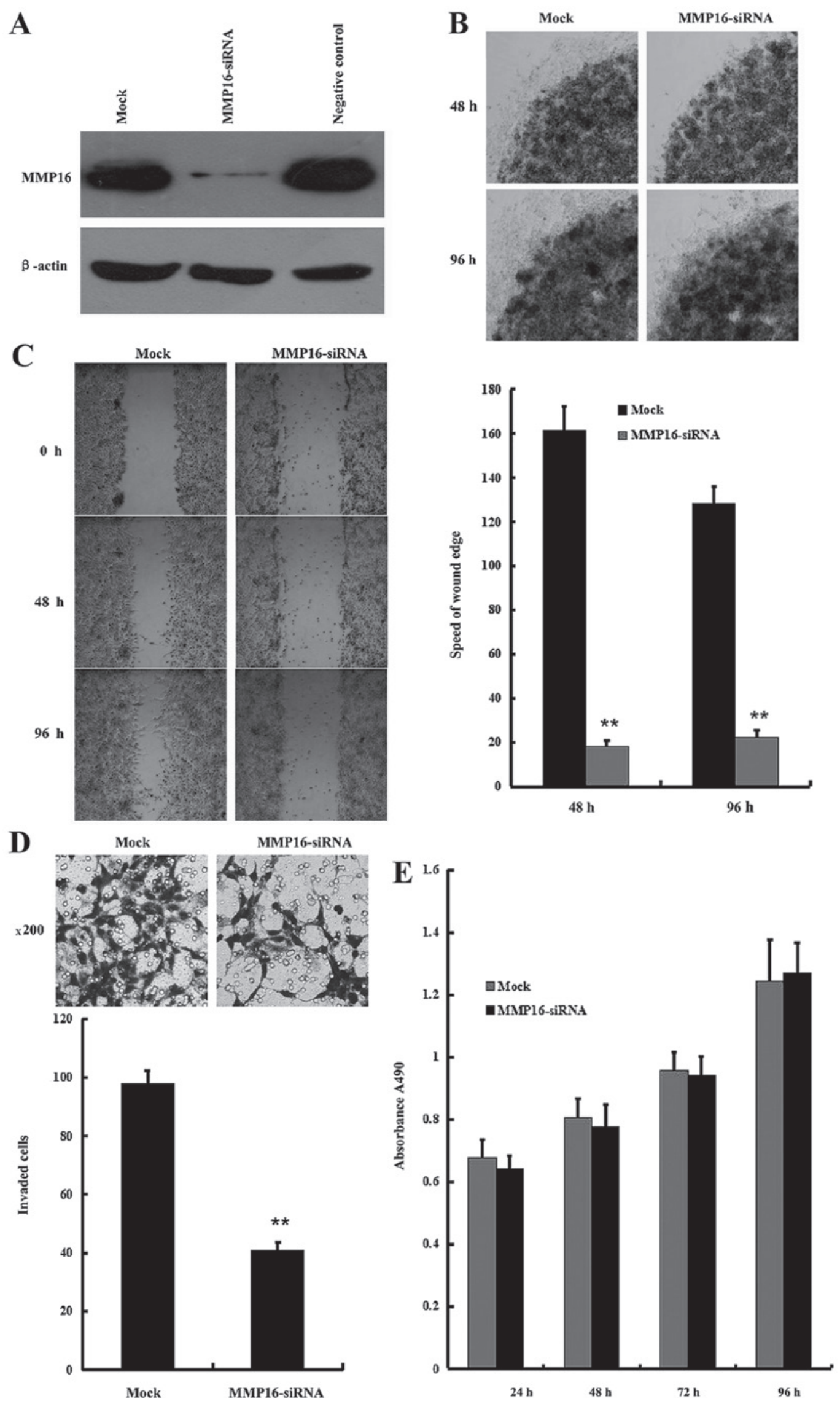

Figure 2. PC3 cell invasion was regulated by MMP16. (A) Endogenous MMP16 was knocked down by MMP16-siRNA in PC3 cells and the negative control siRNA did not affect the expression of MMP16. $\beta$-actin was used for normalization. (B) Knockdown of endogenous MMP16 by MMP16-siRNA decreased the metastatic capacity in PC3 cells by low-melt agarose migration assays. (C) Compared with the Mock group, the MMP16-siRNA transfected group demonstrated lower migration capacity following the $24 \mathrm{~h}$ in vitro wound healing assay $\left({ }^{* * *} \mathrm{P}<0.01\right)$. (D) The invasion capacity of PC 3 cells treated with MMP16-siRNA was measured by Transwell invasion assays ("* $\mathrm{P}<0.01)$. (E) Knockdown of MMP16 did not affect PC3 cellular proliferation in the MTT assay. MMP16, matrix metalloproteinase 16; siRNA, small interfering RNA. 
$\mathbf{A}$

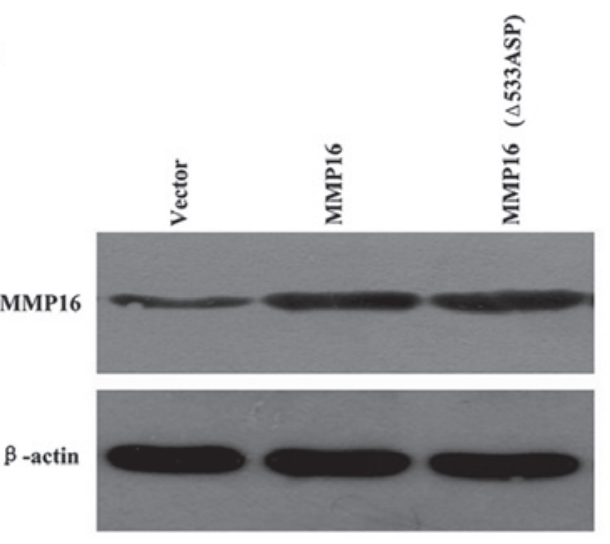

B
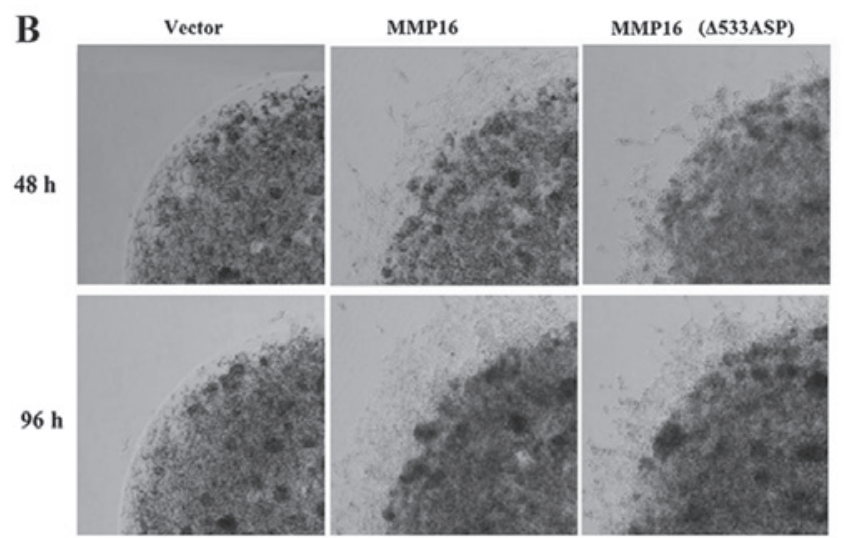

C
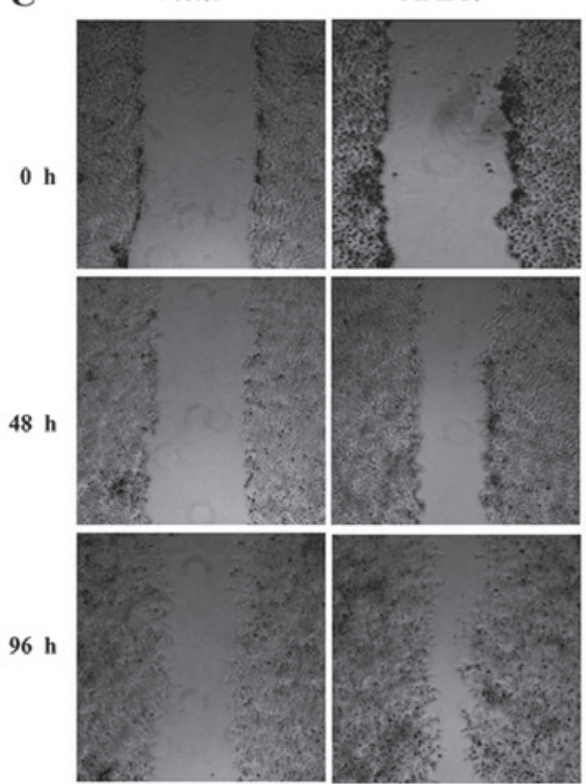

D
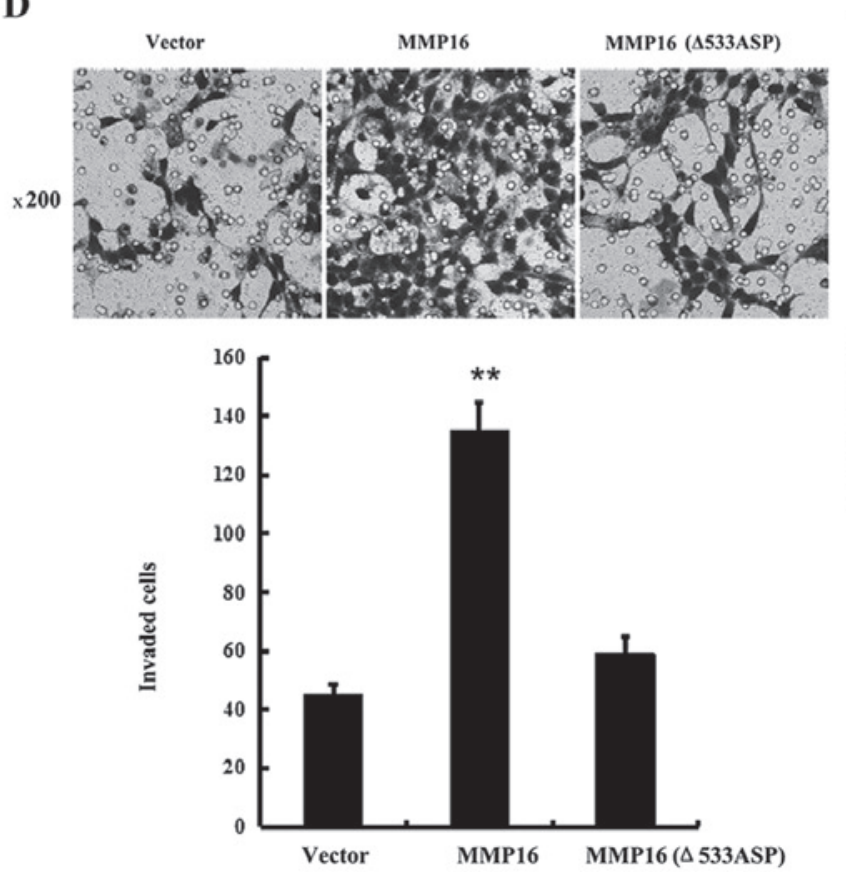

MMP16 $(\triangle 533 A S P)$
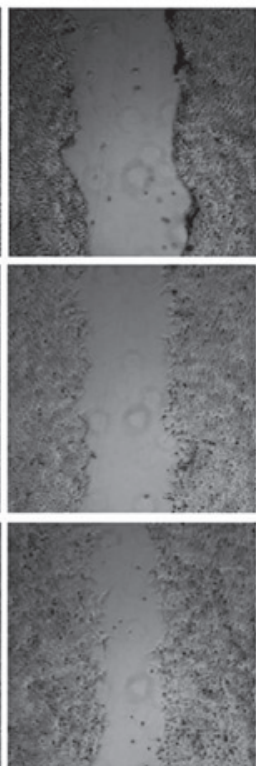

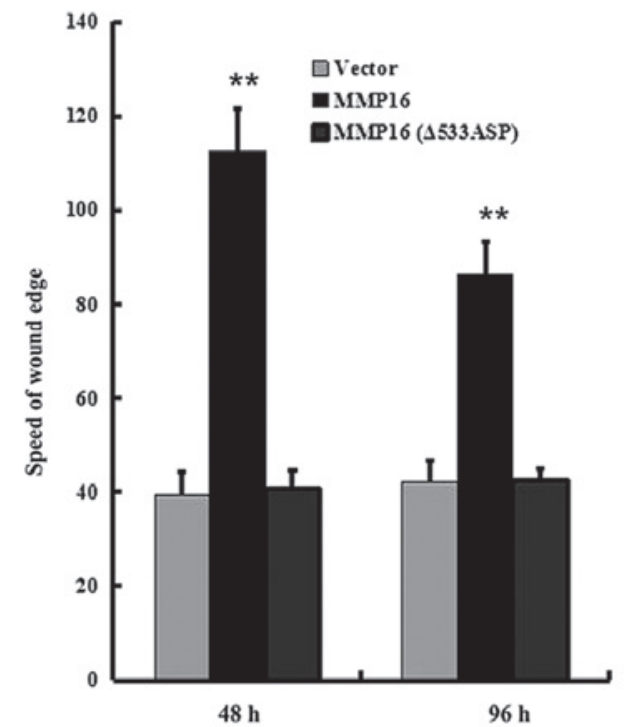

E

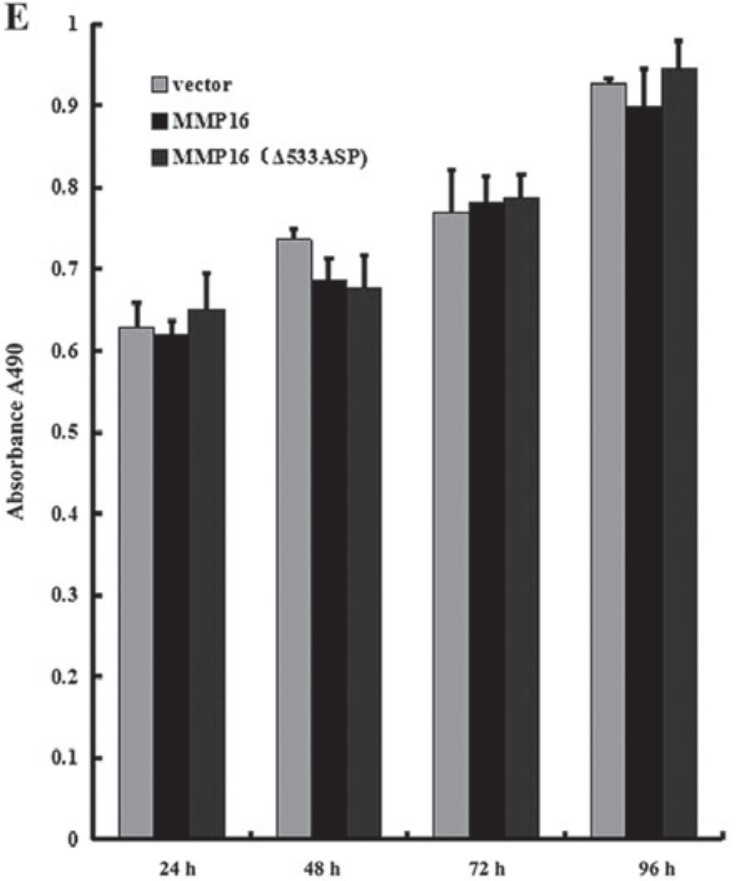

Figure 3. Regulation of LNCaP cell invasion by MMP16 and membrane localization is required. (A) The expression of wild-type MMP16 and MMP16 $(\Delta 533$ Asp) was detected in LNCaP cells. $\beta$-actin was used for normalization. (B) Compared with the wild-type MMP16, the MMP16 ( $\Delta 533$ Asp) group lost the capability to promote migration in low-melt agarose migration assays. (C) Compared with the wild-type MMP16, the MMP16 ( $\Delta 533 \mathrm{Asp})$ group show less migration capacity following the $24 \mathrm{~h}$ in vitro wound healing assay $\left({ }^{* *} \mathrm{P}<0.01\right)$. (D) The MMP16 ( $\Delta 533$ Asp) group demonstrated less invasion capacity compared with the wild-type MMP16 by Transwell invasion assay ( $\left.{ }^{* *} \mathrm{P}<0.01\right)$. (E) MMP16 and MMP16 ( $\left.\Delta 533 \mathrm{Asp}\right)$ did not affect LNCaP cellular proliferation in the MTT assay. MMP16, matrix metalloproteinase 16; Asp, aspartic acid. 


\section{Acknowledgements}

The present study was supported by the Ministry of Science and Technology (grant no. 2016YFE0128500), National Natural Science Foundation of China (grant nos. 30871301 and 30700827), Jilin Provincial Science and Technology Department (grant nos. 20170204009YY, 20150101187JC and 20150414007GH), Jilin Province Education Department (grant nos. 2015-526 and 2015-551) the Fundamental Research Funds for the Central Universities (grant nos. 2412016KJ037, 130017507 and 130028633). University S and T Innovation Platform of Jilin Province for Economic Fungi (grant no. 2014B-1), and the Program for Introducing Talents to Universities (grant no. B07017). The authors would like to thank the organizations mentioned above for their support.

\section{References}

1. Siegel R, Naishadham D and Jemal A: Cancer statistics, 2012. CA Cancer J Clin 62: 10-29, 2012.

2. Grubb RL III and Kibel AS: Prostate cancer: Screening, diagnosis and management in 2007. Mo Med 104: 408-413; quiz 413-404, 2007.

3. Feldman BJ and Feldman D: The development of androgenindependent prostate cancer. Nat Rev Cancer 1: 34-45, 2001.

4. Bejarano PA, Noelken ME, Suzuki K, Hudson BG and Nagase H: Degradation of basement membranes by human matrix metalloproteinase 3 (stromelysin). Biochem J 256: 413-419, 1988.

5. Pei D: Matrix metalloproteinases target protease-activated receptors on the tumor cell surface. Cancer Cell 7: 207-208, 2005.

6. Verma RP and Hansch C: Matrix metalloproteinases (MMPs): Chemical-biological functions and (Q)SARs. Bioorg Med Chem 15: 2223-2268, 2007.

7. Vihinen $P$ and Kähäri VM: Matrix metalloproteinases in cancer: Prognostic markers and therapeutic targets. Int J Cancer 99: 157-166, 2002.

8. Jäälinojä J, Herva R, Korpela M, Höyhtyä M and TurpeenniemiHujanen T: Matrix metalloproteinase 2 (MMP-2) immunoreactive protein is associated with poor grade and survival in brain neoplasms. J Neurooncol 46: 81-90, 2000.

9. Lu N, Ling Y, Gao Y, Chen Y, Mu R, Qi Q, Liu W, Zhang H, $\mathrm{Gu} \mathrm{H}$, Wang $\mathrm{S}$, et al: Endostar suppresses invasion through downregulating the expression of matrix metalloproteinase-2/9 in MDA-MB-435 human breast cancer cells. Exp Biol Med (Maywood) 233: 1013-1020, 2008.

10. Yang B, Tang F, Zhang B, Zhao Y, Feng J and Rao Z: Matrix metalloproteinase-9 overexpression is closely related to poor prognosis in patients with colon cancer. World J Surg Oncol 12: 24, 2014.

11. Gohji K, Fujimoto N, Hara I, Fujii A, Gotoh A, Okada H, Arakawa S, Kitazawa S, Miyake H, Kamidono S and Nakajima M: Serum matrix metalloproteinase- 2 and its density in men with prostate cancer as a new predictor of disease extension. Int J Cancer 79: 96-101, 1998.

12. Moses MA, Wiederschain D, Loughlin KR, Zurakowski D, Lamb CC and Freeman MR: Increased incidence of matrix metalloproteinases in urine of cancer patients. Cancer Res 58: 1395-1399, 1998.

13. Takino T, Sato H, Shinagawa A and Seiki M: Identification of the second membrane-type matrix metalloproteinase (MT-MMP-2) gene from a human placenta cDNA library. MT-MMPs form a unique membrane-type subclass in the MMP family. J Biol Chem 270: 23013-23020, 1995.

14. Lowy AM, Clements WM, Bishop J, Kong L, Bonney T, Sisco K, Aronow B, Fenoglio-Preiser C and Groden J: beta-Catenin/Wnt signaling regulates expression of the membrane type 3 matrix metalloproteinase in gastric cancer. Cancer Res 66: 4734-4741, 2006.

15. Nakada M, Nakamura H, Ikeda E, Fujimoto N, Yamashita J, Sato H, Seiki M and Okada Y: Expression and tissue localization of membrane-type 1, 2 and 3 matrix metalloproteinases in human astrocytic tumors. Am J Pathol 154: 417-428, 1999.
16. Tatti O, Arjama M, Ranki A, Weiss SJ, Keski-Oja J and Lehti K: Membrane-type-3 matrix metalloproteinase (MT3-MMP) functions as a matrix composition-dependent effector of melanoma cell invasion. PLoS One 6: e28325, 2011.

17. Li Y, Wang Y, Yu L, Sun C, Cheng D, Yu S, Wang Q, Yan Y, Kang C, Jin S, et al: miR-146b-5p inhibits glioma migration and invasion by targeting MMP16. Cancer Lett 339: 260-269, 2013.

18. Hotary K, Allen E, Punturieri A, Yana I and Weiss SJ: Regulation of cell invasion and morphogenesis in a three-dimensional type I collagen matrix by membrane-type matrix metalloproteinases 1 , 2 and 3. J Cell Biol 149: 1309-1323, 2000.

19. Ferraro GB, Morrison CJ, Overall CM, Strittmatter SM and Fournier AE: Membrane-type matrix metalloproteinase-3 regulates neuronal responsiveness to myelin through Nogo-66 receptor 1 cleavage. J Biol Chem 286: 31418-31424, 2011.

20. Koc M, Ediger D, Budak F, Karadağ M, Oral HB, Uzaslan E, Ege E and Gözü RO: Matrix metalloproteinase-9 (MMP-9) elevated in serum but not in bronchial lavage fluid in patients with lung cancer. Tumori 92: 149-154, 2006.

21. Kuhlmann KF, van Till JW, Boermeester MA, de Reuver PR, Tzvetanova ID, Offerhaus GJ, Ten Kate FJ, Busch OR, van Gulik TM, Gouma DJ and Crawford HC: Evaluation of matrix metalloproteinase 7 in plasma and pancreatic juice as a biomarker for pancreatic cancer. Cancer Epidemiol Biomarkers Prev 16: 886-891, 2007.

22. Poola I, DeWitty RL, Marshalleck JJ, Bhatnagar R, Abraham J and Leffall LD: Identification of MMP-1 as a putative breast cancer predictive marker by global gene expression analysis. Nat Med 11: 481-483, 2005.

23. Sauer CG, Kappeler A, Späth M, Kaden JJ, Michel MS, Mayer D, Bleyl U and Grobholz R: Expression and activity of matrix metalloproteinases-2 and -9 in serum, core needle biopsies and tissue specimens of prostate cancer patients. Virchows Arch 444: 518-526, 2004.

24. Tetu B, Brisson J, Wang CS, Lapointe H, Beaudry G, Blanchette $\mathrm{C}$ and Trudel D: The influence of MMP-14, TIMP-2 and MMP-2 expression on breast cancer prognosis. Breast Cancer Res 8: R28, 2006.

25. Wood M, Fudge K, Mohler JL, Frost AR, Garcia F, Wang M and Stearns ME: In situ hybridization studies of metalloproteinases 2 and 9 and TIMP-1 and TIMP-2 expression in human prostate cancer. Clin Exp Metastasis 15: 246-258, 1997.

26. Wu ZS, Wu Q, Yang JH, Wang HQ, Ding XD, Yang F and Xu XC: Prognostic significance of MMP-9 and TIMP-1 serum and tissue expression in breast cancer. Int J Cancer 122: 2050-2056, 2008.

27. Nagakawa O, Murakami K, Yamaura T, Fujiuchi Y, Murata J, Fuse $\mathrm{H}$ and Saiki I: Expression of membrane-type 1 matrix metalloproteinase (MT1-MMP) on prostate cancer cell lines. Cancer Lett 155: 173-179, 2000.

28. Ota I, Li XY, Hu Y and Weiss SJ: Induction of a MT1-MMP and MT2-MMP-dependent basement membrane transmigration program in cancer cells by Snail1. Proc Natl Acad Sci USA 106: 20318-20323, 2009.

29. Sato H, Takino T and Miyamori H: Roles of membrane-type matrix metalloproteinase-1 in tumor invasion and metastasis. Cancer Sci 96: 212-217, 2005.

30. Daja MM, Niu X, Zhao Z, Brown JM and Russell PJ: Characterization of expression of matrix metalloproteinases and tissue inhibitors of metalloproteinases in prostate cancer cell lines. Prostate Cancer Prostatic Dis 6: 15-26, 2003.

31. Moon JW, Choi JH, Lee SK, Lee YW, Lee JO, Kim N, Lee HJ, Seo JS, Kim J, Kim HS, et al: Promoter hypermethylation of membrane type 3 matrix metalloproteinase is associated with cell migration in colorectal adenocarcinoma. Cancer Genet 208: 261-270, 2015.

32. Tatti O, Gucciardo E, Pekkonen P, Holopainen T, Louhimo R, Repo P, Maliniemi P, Lohi J, Rantanen V, Hautaniemi S, et al: MMP16 mediates a proteolytic switch to promote cell-cell adhesion, collagen alignment, and lymphatic invasion in melanoma. Cancer Res 75: 2083-2094, 2015

33. Wang H, Li XT, Wu C, Wu ZW, Li YY, Yang TQ, Chen GL, Xie XS, Huang YL, Du ZW and Zhou YX: miR-132 can inhibit glioma cells invasion and migration by target MMP16 in vitro. Onco Targets Ther 8: 3211-3218, 2015.

34. Sato $\mathrm{H}$ and Seiki M: Membrane-type matrix metalloproteinases (MT-MMPs) in tumor metastasis. J Biochem 119: 209-215, 1996. 